\title{
Epstein-Barr Nuclear Antigen Measurement
}

National Cancer Institute

\section{Source}

National Cancer Institute. Epstein-Barr Nuclear Antigen Measurement. NCI Thesaurus.

Code C96604.

The determination of the amount of Epstein-Barr nuclear antigen present in a sample. 